\title{
The Nomological Network of the Short Dark Tetrad Scale (SD4)
}

\author{
Christian Blötner ${ }^{1}$ (D), Matthias Ziegler ${ }^{2}$, Caroline Wehner ${ }^{2}$, Mitja D. Back ${ }^{3}$, \\ and Michael P. Grosz ${ }^{3}$ \\ ${ }^{1}$ Department of Psychology, TU Dortmund University, Germany \\ ${ }^{2}$ Psychologische Diagnostik, Humboldt-Universität zu Berlin, Germany \\ ${ }^{3}$ Department of Psychology, University of Münster, Germany
}

\begin{abstract}
The present study examined the nomological network of the Short Dark Tetrad scale (SD4). The SD4 measures narcissism, psychopathy, Machiavellianism, and sadism. We translated the original English SD4 into German and used an online sample ( $N=594,77 \%$ women) to investigate its nomological network with regard to the Big Five, honesty-humility, maladaptive personality traits, impulsivity, aggression, motives, values, sociosexual orientation, the octants of the interpersonal circumplex model, and self-esteem. The overall profile similarities between the observed and hypothesized nomological networks were very high. Few correlations differed concerning direction or magnitude. Hence, our study extends the nomological network of the Dark Tetrad in a meaningful way and suggests that the SD4 can be validly interpreted and used for the assessment of narcissism, psychopathy, Machiavellianism, and sadism.
\end{abstract}

Keywords: Dark Tetrad, narcissism, Machiavellianism, psychopathy, sadism

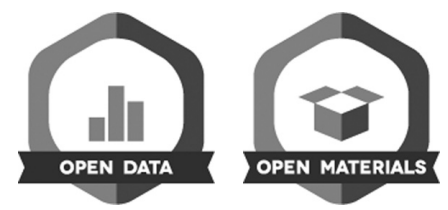

The Short Dark Tetrad scale (SD4) is a personality questionnaire (Paulhus et al., 2020) that was recently developed to measure the four antagonistic traits narcissism, psychopathy, Machiavellianism (Mach), and sadism. The Dark Tetrad is an extension of the Dark Triad (narcissism, psychopathy, and Mach; Paulhus \& Williams, 2002). During the last two decades, a great deal of research has been conducted on the Dark Triad - either as a whole or on its three traits in isolation (Muris et al., 2017). Yet, research on the Dark Tetrad has burgeoned only recently (Chabrol et al., 2009). Paulhus et al. (2020) developed the SD4 to provide a more economical and comprehensive measure of the Dark Tetrad and to sufficiently distinguish the four constructs while retaining the core features of each construct. So far, tests of the nomological network as assessed with the SD4 have been limited. The original SD4 paper investigated relationships with the interpersonal circumplex model, the Big Five, adjustment, and sex drive. A more extensive test of the often-postulated nomological network of the captured traits is needed as a crucial part of the construct validity (Campbell \& Fiske, 1959). The current study expands research on the nomological network of the SD4 and is the first to introduce and validate a German version of the SD4.

Previous research and theory indicate that the constructs captured by the SD4 are related to numerous other constructs and real-life outcomes, ranging from personality to aggressive behavior. In the following, we sketch the most common relations that the nomological network should entail. Table 1 provides a summary of all hypotheses, whereas the preregistration contains derivations of all hypotheses of the nomological network. As a common frame for all estimations, we referred to Gignac and Szodorai's (2016) and Funder and Ozer's (2019) guidelines ( $r s=|.10|,|.20|,|.30|$, and $|.40|$ are deemed small, moderate, high, and very high, respectively).

\section{The Nomological Network of the Dark Tetrad Traits}

\section{Narcissism}

Narcissism is characterized by self-exhibition, a sense of entitlement, and a very high valuation of one's skills and achievements. It can be divided into an agentic, selfpromoting facet (i.e., narcissistic admiration), an antagonistic, self-defending facet (i.e., narcissistic rivalry; Back et al., 2013), and a neurotic, unstable facet (vulnerable narcissism; e.g., Crowe et al., 2019). The narcissism scale of the 
Table 1. Expected and observed nomological networks of the SD4

\begin{tabular}{|c|c|c|c|c|c|}
\hline & SD4-N & SD4-P & SD4-M & SD4-S & SD4 Mean \\
\hline \multicolumn{6}{|l|}{ Narcissism } \\
\hline SD4-N ${ }^{1,2}$ & & $.42(.30)^{b}$ & $.26(.30)^{\mathrm{a}}$ & $.29(.30)^{\mathrm{a}}$ & .71 \\
\hline Admiration ${ }^{1}$ & $.77(.60)^{a, b}$ & $.31(.20)^{b}$ & $.31(.20)^{b}$ & $.17(.10)^{a, b}$ & .56 \\
\hline Rivalry ${ }^{1}$ & $.35(.50)^{\mathrm{b}}$ & $.40(.40)^{\mathrm{a}}$ & $.40(.40)^{\mathrm{a}}$ & $.49(.30)^{b}$ & .57 \\
\hline $\mathrm{NPI}-13^{2}$ & $.59(.70)^{\mathrm{b}}$ & $.30(.40)^{b}$ & $.25(.30)^{a}$ & $.31(.20)^{b}$ & .52 \\
\hline \multicolumn{6}{|l|}{ Psychopathy } \\
\hline SD4- $P^{1,2}$ & $.42(.30)^{\mathrm{b}}$ & & $.19(.30)^{\mathrm{b}}$ & $.54(.50)^{a}$ & .76 \\
\hline$P 7^{1}$ & $.41(.20)^{\mathrm{b}}$ & $.79(.70)^{a, b}$ & $.28(.30)^{a}$ & $.57(.40)^{\mathrm{b}}$ & .72 \\
\hline SRP-III & $.34(.30)^{a}$ & $.71(.70)^{\mathrm{a}}$ & $.27(.40)^{b}$ & $.59(.40)^{\mathrm{b}}$ & .67 \\
\hline \multicolumn{6}{|l|}{ Machiavellianism } \\
\hline SD4-M $M^{1,2}$ & $.26(.30)^{a}$ & $.19(.30)^{b}$ & & $.32(.40)^{b}$ & .61 \\
\hline$M 7^{1}$ & $.21(.20)^{a}$ & $.17(.30)^{b}$ & $.84(.70)^{a, b}$ & $.37(.40)^{a}$ & .55 \\
\hline Mach-IV² & $.23(.30)^{a, b}$ & $.36(.40)^{\mathrm{a}}$ & $.57(.70)^{b}$ & $.55(.40)^{b}$ & .59 \\
\hline \multicolumn{6}{|l|}{ Sadism } \\
\hline SD4-S ${ }^{1,2}$ & $.29(.30)^{\mathrm{a}}$ & $.54(.50)^{\mathrm{a}}$ & $.32(.40)^{b}$ & & .75 \\
\hline VAST $^{2}$ & $.19(.30)^{\mathrm{b}}$ & $.52(.50)^{\mathrm{a}}$ & $.12(.40)^{\mathrm{b}}$ & $.65(.70)^{a, b}$ & .52 \\
\hline \multicolumn{6}{|c|}{ Normal and maladaptive personality } \\
\hline Openness ${ }^{1,2}$ & $.11(.20)^{\mathrm{b}}$ & $-.03(0)^{\mathrm{a}}$ & $-.12(0)^{b}$ & $-.10(0)^{\mathrm{b}}$ & -.04 \\
\hline Conscientiousness ${ }^{1,2}$ & $.01(0)^{\mathrm{a}}$ & $-.37(-.30)^{\mathrm{a}}$ & $-.04(-.10)^{\mathrm{a}}$ & $-.30(-.30)^{a}$ & -.24 \\
\hline Extraversion ${ }^{1,2}$ & $.51(.30)^{\mathrm{b}}$ & $.15(0)^{b}$ & $-.10(0)^{\mathrm{b}}$ & $-.06(.10)^{b}$ & .19 \\
\hline Agreeableness ${ }^{1,2}$ & $-.06(-.20)^{b}$ & $-.34(-.40)^{a}$ & $-.21(-.30)^{b}$ & $-.42(-.40)^{a}$ & -.36 \\
\hline Neuroticism ${ }^{1,2}$ & $-.27(-.20)$ & $.09(0)^{\mathrm{b}}$ & $.02(.10)$ & $.10(-.20)^{b}$ & -.03 \\
\hline $\mathrm{H}-\mathrm{H}^{2}$ & $-.30(-.30)^{\mathrm{a}}$ & $-.26(-.40)^{\mathrm{b}}$ & $-.50(-.40)^{b}$ & $-.38(-.30)^{b}$ & -.50 \\
\hline Negative affectivity ${ }^{1}$ & $0(0)^{a}$ & $.26(0)^{b}$ & $.21(.10)^{\mathrm{b}}$ & $.23(-.10)^{b}$ & .24 \\
\hline Detachment $^{1}$ & $-.17(0)^{b}$ & $.17(.20)^{a}$ & $.29(.20)^{\mathrm{b}}$ & $.24(-.10)^{b}$ & .18 \\
\hline Antagonism ${ }^{1}$ & $.44(.30)^{\mathrm{b}}$ & $.51(.50)^{\mathrm{a}}$ & $.31(.50)^{b}$ & $.51(.50)^{\mathrm{a}}$ & .63 \\
\hline Disinhibition $^{1}$ & $.15(.10)^{a}$ & $.68(.40)^{b}$ & $.15(0)^{b}$ & $.42(.10)^{b}$ & .49 \\
\hline Psychoticism $^{1}$ & $.24(0)^{b}$ & $.56(0)^{b}$ & $.28(0)^{b}$ & $.41(0)^{b}$ & .52 \\
\hline \multicolumn{6}{|l|}{ Impulsivity } \\
\hline Negative urgency ${ }^{1}$ & $.17(0)^{\mathrm{b}}$ & $.55(.20)^{b}$ & $.22(0)^{\mathrm{b}}$ & $.34(0)^{\mathrm{b}}$ & .45 \\
\hline Lack of premeditation ${ }^{1}$ & $.04(0)^{a}$ & $.48(.30)^{b}$ & $-.24(0)^{\mathrm{b}}$ & $.17(0)^{\mathrm{b}}$ & .17 \\
\hline Lack of perseverance ${ }^{1}$ & $-.05(0)^{a}$ & $.25(.30)^{\mathrm{a}}$ & $.08(0)$ & $.26(0)^{\mathrm{b}}$ & .19 \\
\hline Sensation seeking ${ }^{1}$ & $.23(.20)^{\mathrm{a}}$ & $.23(.40)^{\mathrm{b}}$ & $.11(-.10)^{b}$ & $.19(.10)^{b}$ & .27 \\
\hline Positive urgency ${ }^{1}$ & $.29(0)^{b}$ & $.67(.30)^{\mathrm{b}}$ & $.22(-.10)^{b}$ & $.47(0)^{b}$ & .58 \\
\hline \multicolumn{6}{|l|}{ Aggression } \\
\hline Anger $^{2}$ & $.06(.10)^{\mathrm{a}}$ & $.33(.30)^{\mathrm{a}}$ & $.04(.10)^{\mathrm{a}}$ & $.24(.20)^{\mathrm{a}}$ & .24 \\
\hline Physical aggression ${ }^{2}$ & $.18(.10)^{b}$ & $.62(.30)^{b}$ & $.11(0)^{\mathrm{b}}$ & $.50(.40)^{b}$ & .50 \\
\hline Verbal aggression ${ }^{2}$ & $.30(.10)^{b}$ & $.49(.30)^{b}$ & $.13(0)^{b}$ & $.37(.30)^{a}$ & .46 \\
\hline Mistrust $^{2}$ & $-.03(0)^{a}$ & $.33(.20)^{b}$ & $.21(.20)^{a}$ & $.34(0)^{\mathrm{b}}$ & .29 \\
\hline \multicolumn{6}{|l|}{ Personal values } \\
\hline Self-transcendence ${ }^{1}$ & $-.12(0)^{b}$ & $-.20(-.10)^{b}$ & $-.06(-.20)^{b}$ & $-.31(-.20)^{b}$ & -.24 \\
\hline Self-enhancement ${ }^{1}$ & $.53(.30)^{b}$ & $.03(.20)^{\mathrm{b}}$ & $.31(.20)^{b}$ & $.08(.20)^{\mathrm{b}}$ & .34 \\
\hline Openness to change ${ }^{1}$ & $.10(.10)^{\mathrm{a}}$ & $-.04(.10)^{b}$ & $.03(0)^{a}$ & $-.17(0)^{b}$ & -.03 \\
\hline Conservation $^{1}$ & $.06(-.10)^{b}$ & $-.23(-.10)^{b}$ & $.15(-.10)^{b}$ & $-.12(-.10)^{\mathrm{a}}$ & -.05 \\
\hline \multicolumn{6}{|l|}{ Unified motives } \\
\hline Hope for achievement ${ }^{1}$ & $.18(.30)^{b}$ & $-.11(.20)^{b}$ & $.11(.20)^{\mathrm{b}}$ & $-.10(.10)^{b}$ & .03 \\
\hline Hope for power ${ }^{1}$ & $.72(.30)^{\mathrm{b}}$ & $.30(.20)^{\mathrm{b}}$ & $.25(.30)^{a}$ & $.22(.20)^{a}$ & .54 \\
\hline Hope for affiliation ${ }^{1}$ & $.24(-.20)^{b}$ & $-.09(-.30)^{b}$ & $-.12(-.20)^{b}$ & $-.20(-.20)^{a}$ & -.05 \\
\hline Fear of loss $^{1}$ & $-.16(-.20)^{\mathrm{a}}$ & $-.09(-.10)^{\mathrm{a}}$ & $.14(.10)^{\mathrm{a}}$ & $-.03(0)^{\mathrm{a}}$ & -.05 \\
\hline
\end{tabular}


Table 1. (Continued)

\begin{tabular}{|c|c|c|c|c|c|}
\hline & SD4-N & SD4-P & SD4-M & SD4-S & SD4 Mean \\
\hline \multicolumn{6}{|c|}{ Dominance, prestige, and leadership } \\
\hline Dominance $^{2}$ & $.41(.20)^{b}$ & $.46(.20)^{b}$ & $.42(.20)^{b}$ & $.50(.20)^{b}$ & .63 \\
\hline Prestige $^{2}$ & $.33(.30)^{a}$ & $.01(0)^{a}$ & $.34(0)^{b}$ & $.07(0)^{a, b}$ & .27 \\
\hline Leadership $^{2}$ & $.63(.30)^{b}$ & $.25(.20)^{\mathrm{a}}$ & $.14(.10)^{\mathrm{a}}$ & $.20(0)^{\mathrm{b}}$ & .44 \\
\hline $\mathrm{SSO}^{2}$ & $.14(.30)^{b}$ & $.34(.30)^{\mathrm{a}}$ & $0(.20)^{b}$ & $.18(.20)^{\mathrm{a}}$ & .24 \\
\hline \multicolumn{6}{|c|}{ Interpersonal circumplex } \\
\hline Assertiveness $^{1}$ & $.54(.30)^{\mathrm{b}}$ & $.20(.20)^{\mathrm{a}}$ & $-.05(.10)^{\mathrm{b}}$ & $.01(0)^{\mathrm{a}}$ & .26 \\
\hline Cynicism ${ }^{1}$ & $.28(.20)^{b}$ & $.45(.20)^{b}$ & $.19(.30)^{b}$ & $.39(.20)^{b}$ & .46 \\
\hline Hostility $^{1}$ & $.24(.20)^{a}$ & $.42(.30)^{b}$ & $.24(.20)^{\mathrm{a}}$ & $.53(.30)^{b}$ & .51 \\
\hline Unsociability ${ }^{1}$ & $-.19(-.10)^{\dagger, b}$ & $.11(.20)^{b}$ & $.19(.20)^{a}$ & $.22(.20)^{a}$ & .11 \\
\hline Shyness ${ }^{1}$ & $-.39(-.20)^{b}$ & $-.15(-.20)^{\mathrm{a}}$ & $.16(-.10)^{b}$ & $.01(0)^{a}$ & -.14 \\
\hline Obedience $^{1}$ & $-.22(-.20)^{\mathrm{a}}$ & $-.29(-.20)^{\mathrm{b}}$ & $.13(0)^{b}$ & $-.14(-.20)^{\mathrm{a}}$ & -.19 \\
\hline Empathy ${ }^{1}$ & $-.09(-.20)^{b}$ & $-.38(-.30)^{b}$ & $-.08(-.20)^{b}$ & $-.41(-.20)^{b}$ & -.34 \\
\hline Sociableness ${ }^{1}$ & $.35(.10)^{t, b}$ & $.01(-.20)^{b}$ & $0(-.20)^{b}$ & $-.12(-.20)^{b}$ & .10 \\
\hline Self-esteem ${ }^{2}$ & $.29(.30)^{a}$ & $-.17(0)^{b}$ & $0(.10)^{b}$ & $-.18(0)^{b}$ & -.01 \\
\hline
\end{tabular}

Note. SD4-N, -P, -M, -S, = Narcissism, Psychopathy, Machiavellianism, and Sadism, as measured by the SD4; NPI-13 = 13-item version of the Narcissistic Personality Inventory; $\mathrm{H}-\mathrm{H}=$ Honesty-Humility; SSO = Sociosexual Orientation. ${ }^{1}$ Presented in Condition $1\left(n_{1}=271\right) ;{ }^{2}$ Presented in Condition $2\left(n_{2}=323\right)$. Values in parentheses are hypothesized $r s .{ }^{\dagger}$ In Table 1 in the preregistration, correlations of narcissism with unsociability and sociableness were labeled with incorrect signs ( $r s=.10$ and -.10 ), whereas in the text, the correct signs were mentioned. ${ }^{\mathrm{a} C}$ Correlation was within the boundaries $(p<.05) ;{ }^{b} \mathrm{Correlation}$ was different from the expected $r(p<.05)$.

SD4 focuses more strongly on the agentic than on the antagonistic and vulnerable facet. We expected a large positive correlation between SD4 narcissism and extraversion because individuals with high scores in narcissism engage in social interactions to seek confirmation (Morf \& Rhodewalt, 2001). This effect size is in line with metaanalytical results (Muris et al., 2017; Vize et al., 2018). Further considering high narcissistic individuals' beliefs of grandiosity and uniqueness (Back et al., 2013), we expected large positive correlations with self-enhancement values, motivation for prestige, assertiveness, and self-esteem. We expected a moderate, negative correlation between SD4 narcissism and neuroticism (see Back et al., 2013, for a similar correlation for narcissistic admiration).

\section{Psychopathy}

Psychopathy is defined by impulsive, aggressive, irresponsible, and socially aversive behaviors (e.g., Skeem et al., 2011). We expected large positive correlations with both key components of impulsivity (Whiteside \& Lynam, 2001): Lack of premeditation (i.e., preference for non-reflected behaviors over long-term planning) and lack of perseverance (i.e., low stamina on dull tasks). Following meta-analyses (Muris et al., 2017; Vize et al., 2018), we expected large positive correlations with physical and verbal aggression. Addressing selfishness and irresponsibility, we attempted to roughly replicate Balakrishnan et al.'s (2017) finding on self-transcendence values $(r=-.10)$.

\section{Machiavellianism}

Prominent characteristics of Machiavellianism are planfulness, manipulation, immorality, and a cynical worldview (Christie \& Geis, 1970). Dahling et al. (2009) emphasized distrust and fear of being deceived, which the authors linked with affective lability. We expected small and moderate positive correlations with neuroticism and mistrust, respectively. Mach should be more strongly positively associated with self-control and less positively with aggression than psychopathy (Paulhus et al., 2018). Therefore, we expected null correlations of Mach with lack of perseverance, physical aggression, and verbal aggression. Given the role of cynicism in Mach, we hypothesized a large positive correlation with cynicism.

\section{Sadism}

Highly sadistic individuals enjoy doing or viewing harm (direct and vicarious sadism, respectively; Paulhus \& Jones, 2015). The research mentions verbal and physical violence but physical violence is more typical for sadism (Paulhus et al., 2020). We, therefore, expected sadism to reveal large and very large positive correlations with verbal and physical aggression, respectively. Because sadistic aggression is seen as a means to feel dominant (e.g., Buckels et al., 2018), we expected a moderately positive correlation with dominance. Considering intentional violence and trivializing others' pain (Buckels et al., 2018), and in line with Southard et al. (2015), we expected a moderate, negative correlation with empathy. 


\section{The Dark Tetrad Traits' Shared Variance}

The Dark Tetrad is a combination of disagreeable traits (Chabrol et al., 2009). Thus, we expected negative correlations with agreeableness for all four traits. Because the present narcissism scale is rather agentic and less antagonistic, we expected a moderately negative correlation with agreeableness. For psychopathy, we referred to recent meta-analyses (Muris et al., 2017; Vize et al., 2018) and hypothesized a very large positive correlation with agreeableness. For Mach, we expected a smaller correlation than was found in these meta-analyses $(r=-.30)$. The metaanalyses focused on findings from Mach scales that correlated more strongly with psychopathy than the Mach scale of the SD4 is supposed to (Paulhus et al., 2020). Following Book et al. (2016), we expected a very strong negative correlation of sadism with agreeableness.

\section{Method}

\section{Participants and Procedure}

We recruited our participants via social media. Only adults were allowed to participate. A lottery for ten $25 €$ shopping vouchers, scientifically based feedback on the personality (Big Five), and/or course credit served as incentives. All participants filled out demographic questionnaires, the SD4, and a Big Five measure. Afterward, participants were randomly assigned to one of two conditions in which only a subset of the items was administered (planned missingness design; e.g., Enders, 2010; for the assignment, see Table 1). We took care of having equal numbers of items and at least one additional narcissism, psychopathy, and Mach scale in each condition. Following Schönbrodt and Perugini's (2013) sample size recommendation for estimating stable correlation coefficients, we aimed to have at least 250 participants in each condition. To compensate for exclusions and unequal partitioning at the outset, we recruited 600 participants (i.e., in both conditions combined). We excluded six participants because they were under 18 years old $(n=2)$ or due to technical problems in the assignment $(n=4)$. The final sample size was 594 (77\% women, $M_{\text {age }}=28.4, S D_{\text {age }}$ =9.0) with 271 in Condition 1 and 323 in Condition 2. This study received approval from the institutional review board of the University of Münster.

\section{Measures}

\section{Dark Tetrad Traits}

Narcissism was measured with our German translation of the SD4 narcissism scale (Paulhus et al., 2020), the German short form of the Narcissistic Admiration and Rivalry
Questionnaire (NARQ-S; Leckelt et al., 2018), and a 13-item German version of the Narcissistic Personality Inventory (NPI-13; Brailovskaia et al., 2019). Psychopathy was measured with our German translation of the respective SD4 scale, a self-translated version of the 28-item Self-Report Psychopathy Scale-III (SRP-III; Gordts et al., 2015), and the German P7 (Grosz et al., 2020). Mach was measured with our German translation of the SD4 Mach scale, a German version of the Mach-IV (Henning \& Six, 1977), and the German M7 (Grosz et al., 2020). Sadism was measured with our German translation of the SD4 scale and a German translation of the Varieties of Sadistic Tendencies (VAST; Paulhus \& Jones, 2015) as used in Wehner et al. (2020). The German translation of the SD4 is presented in the Appendix. Two groups of two researchers each translated the items independently and, in cases of disagreement, reached a consensus for the translations. Table S1 in the supplement provides more information concerning the measures' compositions of subscales, numbers of items, descriptive statistics, internal consistency estimates, and rating scales (https://osf.io/9ewjr/).

\section{Broad Personality Traits}

For the assessment of the Big Five, we used Danner et al.'s (2016) German version of the Big Five Inventory-2. We measured Honesty-Humility $(\mathrm{H}-\mathrm{H})$ with the respective subscale from Moshagen et al.'s (2014) German HEXACO-60. For maladaptive personality traits, we used Zimmermann et al.'s (2014) German short form of the Personality Inventory for DSM-5.

\section{Impulsivity}

To measure the facets of Negative Urgency, Premeditation (reverse-scored), Perseverance (reverse-scored), and Sensation Seeking, we applied the German short form of the Urgency Premeditation Perseverance and Sensation Seeking Impulsive Behavior Scale (Keye et al., 2009; original by Whiteside \& Lynam, 2001). To measure Positive Urgency, we used self-translated versions of Cyders et al.'s (2014) positive urgency scale and Cyders et al.'s (2007) item "When I am very happy, I feel like it is OK to give in to cravings or overindulge."

\section{Aggression}

We assessed Physical Aggression, Verbal Aggression, Anger, and Mistrust with the German Aggression Scale (Werner $\&$ von Collani, 2014).

\section{Personal Values}

Self-Transcendence, Self-Enhancement, Openness to Change, and Conservation were measured with Beierlein et al.'s German Personal Values Scales (GESIS, 2014). 


\section{Motives}

We used the German Unified Motives Scale (Schönbrodt \& Gerstenberg, 2012) to measure Hope for Power, Hope for Achievement, Hope for Affiliation, and Fear of Loss.

\section{Dominance, Prestige, and Leadership}

To measure the motivations for Dominance, Prestige, and Leadership, we used Suessenbach et al.'s (2019) respective scales.

\section{Sociosexual Orientation}

Sociosexual Orientation (SSO) was measured with the German Revised Sociosexual Orientation Inventory (Penke, 2011).

\section{Interpersonal Circumplex}

The octants of the Interpersonal Circumplex were assessed with the German short form of the Interpersonal Adjective List (Jacobs \& Scholl, 2016).

\section{Self-Esteem}

To measure Self-Esteem, we used von Collani and Herzberg's (2003) German version of the Rosenberg Self-Esteem Scale.

\section{Analytic Strategy}

We based our analyses on bivariate product-moment correlations between the SD4 traits and the presented criteria. Different from the preregistered plan of calculating all results with the subsample sizes on which each correlation was based (random Conditions 1 and 2), we imputed missing mean values (50 imputations) with the R-package mice (version 3.11.0; van Buuren, 2020). We then evaluated the congruence between each Dark Tetrad trait's hypothesized and observed nomological networks (profile similarity), the agreement between the observed nomological networks of the SD4 traits, and the agreement of the hypothesized and observed correlations for each combination of Dark Tetrad trait and criterion (equivalence test). Thus, equivalence tests enabled us to identify high and low contributions to overall profile similarity.

\section{Profile Similarity Between Expected and Observed Nomological Networks of the SD4}

For the profile similarity analyses, we used the ContrastConstruct Validity method (CCV; Furr \& Heuckeroth, 2019). That is, we correlated contrast-weighted expected correlations and Fisher-z-transformed actual correlations with each other ( $\left.r_{\text {alerting-CV }}\right)$. This bare-bones correlation quantifies agreement regardless of numerical similarities. An adjusted index, $r_{\text {contrast-CV, additionally integrates infor- }}$ mation regarding the variance of hypothesized correlations and the shape of the empirical correlations' distribution. It is more informative than $r_{\text {alerting-Cv }}$ and thus, we preferred

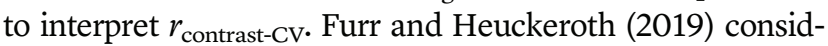
ered profile similarity indices around .70 or larger as good congruence. To run the analyses, we used the R-package $q c v$ (version 1.0; Furr \& Heuckeroth, 2018).

\section{Comparisons of the Observed Nomological Networks of the SD4 Traits}

To compare the observed nomological networks between the four traits, we computed double-entry intraclass correlations $\left(\mathrm{ICC}_{\mathrm{DE}}\right.$ ) with the R package iccde (version 0.3.1, Blötner \& Grosz, 2021). This analysis was based on the observed correlations of the SD4 traits with the traits of the nomological networks (excluding intercorrelations among the SD4 traits). Hence, the CCV method (Furr \& Heuckeroth, 2019) tests the agreement between expected and observed correlations for each SD4 trait in particular, whereas the $\mathrm{ICC}_{\mathrm{DE}} \mathrm{S}$ quantify the agreement of the observed correlations between two different SD4 traits. This analysis was based on a reviewer's recommendation.

\section{Equivalence Test}

The procedure of testing equivalence between expected and observed correlations consists of two one-sided tests (TOSTs; Lakens, 2017). We tested whether an observed correlation was significantly larger than a lower equivalence bound while simultaneously being significantly smaller than an upper equivalence bound. The equivalence bounds depended on the smallest effect size that could yield significance, given the actual statistical power (smallest effect size of interest; SESOI). Lower and upper boundaries resulted from subtracting the SESOI from the expected correlation and adding the SESOI to the expected correlation, respectively. To identify the SESOI, we used the R-package pwr (version 1.3-0; Champely et al., 2020). Given $N=594$ and a target power of $95 \%$, the analysis revealed SESOI = |.13|. Equivalence tests were computed with the R-package TOSTER (version 0.3.4; Lakens, 2017). In addition to the preregistered equivalence tests, we tested whether each observed correlation was significantly different from its expected correlation by using the R-package diffcor (version 0.6.4; Blötner, 2021). We decided to do so because empirical correlations can be within the equivalence bounds, but their confidence intervals might not overlap with the expected value (Lakens, 2017). Considering both equivalence tests and correlation difference tests enabled us to evaluate the findings in a more differentiated way. When the TOSTs were significant (both $p s_{\mathrm{TOST}}<.05$ ) and the difference test was not significant $\left(p_{\text {diff }} \geq .05\right)$, we concluded equivalence between the expected and observed coefficients. When the observed correlation differed significantly from the hypothesized correlation $\left(p_{\text {diff }}<.05\right)$, but only one 
of the TOSTs was significant, we interpreted this to indicate nonequivalence. Finally, we treated a finding as being inconclusive if (a) both TOSTs and the correlation difference test yielded significance or (b) none of the tests yielded significance.

\section{Results and Discussion}

\section{Confirmatory Factor Analyses (CFA)}

Before we conducted our main analyses, we replicated Paulhus et al.'s (2020) confirmatory factor analyses with and without parceling (Weighted Least Square Mean and Variance Adjusted [WLSMV] estimator from the R package lavaan version 0.6-7; Rosseel, 2012; see Tables S2-S7). Without parceling, the model fit was poor with regard to the Comparative Fit Index (CFI) but acceptable with regard to Root Mean Square Error of Approximation (RMSEA) and Standardized Root Mean Square Residual (SRMR) (Hu \& Bentler, 1999), $\chi^{2}(344)=963.12, p<.001, \mathrm{CFI}=.78$, RMSEA $=.06,90 \% \mathrm{CI}=[.05, .06]$, SRMR $=.07$. Modification indices especially suggested cross-loadings of the items onto other factors. The fit improved with parceling (random assignment of 2, 2, and 3 items to each parcel per factor), $\chi^{2}(48)=157.50, p<.001$, CFI $=.92$, RMSEA $=.06,90 \%$ $\mathrm{CI}=[.05, .07]$, SRMR $=.04$. Paulhus et al.'s (2020) CFAs had similar RMSEAs and SRMRs but higher CFIs. However, $\mathrm{Hu}$ and Bentler's benchmarks are based on simulations with extremely high factor loadings. These conventions are inappropriate in models with more realistic loadings (Heene et al., 2011). Our results are thus in line with many other studies that used questionnaire data (Hopwood \& Donnellan, 2010).

Table 1 presents the correlations between the SD4 scales and the constructs from the nomological network. Our supplement provides the details of all used instruments (reliability estimators, descriptive statistics, information on subscales, response scales; Table S1, https://osf.io/9ewjr/), CFAs of the SD4 (Tables S2-S7, https://osf.io/9ewjr/), all results of our equivalence tests (Table S8, https://osf.io/ 9ewjr/), a comparison of our results with and without imputation (Table S9, https://osf.io/9ewjr/), a comparison of the results for native-speakers and non-native speakers (robustness analysis; Table S10, https://osf.io/9ewjr/), and the ICC $_{\mathrm{DE}} \mathrm{S}$ (Table S11, https://osf.io/9ewjr/).

\section{Narcissism}

For the congruence between the hypothesized and observed correlations involving SD4 narcissism, the profile similarity indices were $r_{\text {alerting-CV }}=.81$ and $r_{\text {contrast-CV }}=.95$. That is, the rank orders of the expected and observed coefficients revealed a correlation of .81. After correcting the biases that were due to the distribution properties of the observed and expected coefficients, the correlation between the observed and expected values was .95. This indicates that many of our observations converged with our expectations in terms of direction (Furr \& Heuckeroth, 2019). Similarly, 19 of the 52 equivalence tests indicated that the hypothesized and observed correlations were equivalent. For example, the observed correlations of narcissism with the motivation for prestige $(r=.33)$ and selfesteem $(r=.29)$ were significantly within the boundaries (both expected $\left.r \mathrm{~s}=.30, \mathrm{ps}_{\mathrm{TOST}} \leq .002\right)$ and were not different from the expected values $\left(p s_{\text {diff }} \geq .42\right)$. Thus, we concluded that equivalence held. For the correlation between self-esteem and narcissistic admiration, Back et al. (2013) found a similar effect size. For neuroticism and admiration, our findings were inconclusive because neither $(r=-.27$; expected $r=-.20$, all $p s \leq .07)$ or both tests were significant, respectively $(r=.77$, expected $r=.60$, all $p$ s $<.001)$. Finally, we concluded that non-equivalence held when the observed and hypothesized parameters differed, while only one of the TOSTs was significant. We found nonequivalence for 30 of 52 correlations. For instance, we observed correlations that were higher than expected for criteria reflecting grandiose exhibition and self-promotion (Back et al., 2013): These were the correlations with extraversion $(r=.51)$, self-enhancement values $(r=.53)$, and assertiveness $(r=.54$, all expected $r s=.30)$. Furthermore, we found a correlation with agreeableness that was smaller than expected $\left(r=-.06\right.$, expected $r=-.20, p \mathrm{~s}_{\mathrm{TOST}}$ $\left.\leq 1.00, p s_{\text {diff }}<.001\right)$. Last, the narcissism scale from the SD4 revealed stronger than expected correlations with physical and verbal aggression $(r s=.18$ and .30 , both expected $r s=.10)$ and antagonism $(r=.44$, expected $r=$ $\left..30, p_{\text {diff }}<.05, p \mathrm{~s}_{\mathrm{TOST}} \leq .97\right)$. Paulhus et al. (2020) found similar correlations with neuroticism, agreeableness, and extraversion. Given that the aggression-, antagonism-, and self-promotion-links were stronger than expected, we concluded that the SD4 narcissism scale might not only assess agentic but also partly antagonistic narcissism.

\section{Psychopathy}

For the congruence between hypothesized and observed correlations involving SD4 psychopathy, profile similarity indices were $r_{\text {alerting-CV }}=.84$ and $r_{\text {contrast-CV }}=.95$. We concluded that equivalence held for 18 of 52 correlations. For example, the observed and expected correlations were equivalent for lack of perseverance $(r=.25$, expected $r=$ .30) and agreeableness $(r=-.34$, expected $r=-.40)$. The equivalent correlations we found corroborated aversive, uncontrolled tendencies in psychopathy (Skeem et al., 2011). On the contrary, physical $(r=.62)$ and verbal 
aggression $(r=.49$, both expected $r \mathrm{~s}=.30)$, and selftranscendence values $\left(r=-.20, r=-.10, p \mathrm{~s}_{\mathrm{TOST}}<1.00\right.$, $\left.p_{\text {diff }}<.01\right)$ were closer related to psychopathy than we expected. These correlations and an additional 30 other correlations were not equivalent (see Table 1). However, the directions and strengths of the correlations emphasize the validity of the SD4 subscale as the stated constructs refer to central characteristics. For example, the psychopathy subscale of the SD4 explicitly names conflicts with others and with authorities. A positive, non-equivalent correlation with neuroticism $\left(r=.09\right.$, expected $r=0, p_{\text {diff }} \leq$ $\left..03, p \mathrm{~s}_{\mathrm{TOST}} \leq .16\right)$ emphasizes the emotionally unstable side of psychopathy, whereas, for instance, the inverse, very high correlation with empathy $(r=-.38$, expected $r=$ $-.30, p_{\text {diff }}=.03, p_{\text {TOST }}=.07$ ) indicates parallels with the callous facets of psychopathy (Skeem et al., 2011).

\section{Machiavellianism}

For SD4 Mach, the profile similarity indices were $r_{\text {alerting-CV }}=.77$ and $r_{\text {contrast-CV }}=.94$. For 13 of 52 correlations, equivalence between observation and expectation held (see Table 1). Among others, the correlation with mistrust $\left(r=.21\right.$, expected $\left.r=.20, p \mathrm{~s}_{\mathrm{TOST}} \leq .001, p_{\text {diff }}=.80\right)$ was equivalent to our expectation. Combining this finding with a negative correlation with a lack of premeditation $(r=-.24$, expected $r=0)$, our results underlined long-term planning and skepticism of others (Dahling et al., 2009). On the other hand, we found small, non-equivalent correlations with physical and verbal aggression $(r s=.11$ and .13 , respectively, both expected $r \mathrm{~s}=0, p \mathrm{~s}_{\mathrm{TOST}}<.50, p \mathrm{~s}_{\text {diff }} \leq$ .001). These correlations disagreed with the Machiavellian tendency to avoid violence (Paulhus et al., 2018) but were smaller than findings from earlier studies that were based on measures that revealed stronger overlaps with psychopathy (Muris et al., 2017; Vize et al., 2018). Likewise, the agreement of the observed nomological networks of SD4 Mach and SD4 psychopathy ( $\mathrm{ICC}_{\mathrm{DE}}=.33$; see Table S11, https://osf.io/9ewjr/) was smaller than the agreement found for other Mach and psychopathy scales (e.g., Miller et al., 2017). The correlation between SD4 Mach and neuroticism was inconclusive $\left(r=.02\right.$, expected $r=.10, p \mathrm{~s}_{\mathrm{TOST}}$ $\left.\leq .11, p_{\text {diff }}=.051\right)$. Relatedly, Muris et al.'s (2017) meta-analysis suggested that the link between neuroticism and Mach varies from Mach scale to Mach scale. Some correlations were not equivalent but were in the predicted direction and relatively close to the expected values, for example, the correlations with cynicism $(r=.19$, expected $r=.30)$ and agreeableness $\left(r=-.21\right.$, expected $r=-.30, p \mathrm{~s}_{\mathrm{TOST}}<$ $\left..16, p s_{\text {diff }} \leq .02\right)$. However, the current Mach scale has remarkably less cynical or overtly disagreeable item content than other scales (e.g., Mach-IV) and rather emphasizes strategic orientations. This might have accounted for smaller than expected correlations with agreeableness and cynicism.

\section{Sadism}

Profile similarity indices for the congruence between expected and observed correlations in sadism were $r_{\text {alerting-CV }}=.83$ and $r_{\text {contrast-CV }}=.95$. Seventeen of 52 observed correlations were equivalent to the expected correlations and thus contributed to high profile similarity. For example, the correlations with agreeableness $(r=-.42$, expected $r=-.40$; for a similar correlation, see Paulhus et al., 2020) and verbal aggression $(r=.37$, expected $r=$ $\left..30, p s_{\mathrm{TOST}} \leq .04, p \mathrm{~s}_{\mathrm{diff}}>.05\right)$ were equivalent. However, we found more extreme correlations than expected for physical aggression $(r=.50$, expected $r=.40)$, empathy $(r=-.41$, expected $r=-.20)$, and dominance $(r=.50$, expected $\left.r=.20, p \mathrm{~s}_{\mathrm{TOST}}<1.00, p \mathrm{~s}_{\mathrm{diff}} \leq .002\right)$. Other sadism scales were also associated with high aggression and dominance and low empathy, but the effect sizes for these other scales were smaller (Dinić et al., 2020). An explanation for this discrepancy might be that the sadism scale from the SD4 is less affected by variance restriction than other sadism scales because SD4 sadism measures more common forms of sadism (e.g., SD4 sadism: "It's funny when idiots fall flat on their face" vs. VAST: "In video games, I like the realistic blood spurts"). ${ }^{1}$ However, sadism and psychopathy as measured by the SD4 were strongly correlated with each other $(r=.54)$ and quite similar in their nomological networks $\left(\mathrm{ICC}_{\mathrm{DE}}=.88\right.$, see Table S11, https://osf.io/9ewjr/). Thus, the overlap between SD4 sadism and SD4 psychopathy should be probed by future research.

We compared the results we obtained with and without imputation. Due to higher statistical power, a higher amount of the observed correlations was not equivalent to the expected correlations when missing data were imputed. Many of these correlations were equivalent when missing data were not imputed. This further underlines the strictness of our analyses. Note that only a few parameters differed between the analyses with and without imputations (see Table S9, https://osf.io/9ewjr/).

\section{Conclusions and Limitations}

By offering a broadband validation, this project provided further insights into the nomological network of the SD4 while simultaneously presenting a German version.

1 Furthermore, the dominance scale we employed strongly related to high agency but low communion (i.e., Quadrant II from the IPC). Antagonistic traits typically project on Quadrant II (Jones \& Paulhus, 2011), which explains the very high correlation between dominance and SD4 sadism. 
Although only about a third of our hypotheses on equivalence were supported, our findings can be interpreted in favor of the construct validity because most correlations were in the expected direction (as can be seen in the profile similarity indices) and many were relatively close to previously observed correlations. It should be noted that our analyses were very strict so that non-equivalence of correlations resulted quite easily. Relatively similar effect sizes were equivalent or not equivalent, depending on the sample size (see Table S9, https://osf.io/9ewjr/). Another possible way to define the boundaries for the equivalence tests would have been to test if the observed correlations differed from the expected ones by more than $r=|.20|$ (moderate effect size according to Gignac \& Szodorai, 2016). Under these circumstances, more correlations would have yielded equivalence.

This study was confronted with some limitations. First, we only used cross-sectional self-report data. Second, our sample was imbalanced in that it predominantly comprised women, and it is men who tend to score higher on dark traits (Chabrol et al., 2009; Muris et al., 2017). Third, we did not test the measurement invariance of the SD4 across language groups (English vs. German). To overcome the shortcomings, we encourage future research to investigate the psychometric properties of the SD4 in more genderbalanced samples. Future research should also test the measurement invariance of the German version of the SD4.

\section{References}

Back, M. D., Küfner, A. C. P., Dufner, M., Gerlach, T. M., Rauthmann, J.F., \& Denissen, J. J. A. (2013). Narcissistic admiration and rivalry: Disentangling the bright and dark sides of narcissism. Journal of Personality and Social Psychology, 105 (6), 1013-1037. https://doi.org/10.1037/a0034431

Balakrishnan, A., Plouffe, R. A., \& Saklofske, D. H. (2017). What do sadists value? Is honesty-humility an intermediary? Replicating and extending findings on the link between values and "dark" personalities. Personality and Individual Differences, 109, 142147. https://doi.org/10.1016/j.paid.2016.12.055

Blötner, C. (2021). diffcor: Fisher's z-tests concerning difference of correlations (R package version 0.6.4). CRAN. https://CRAN.Rproject.org/package $=$ diffcor

Blötner, C., \& Grosz, M.P. (2021). iccde: Computation of the double-entry intraclass correlation ( $\mathrm{R}$ package version 0.3.1). CRAN. https://cran.r-project.org/web/packages/iccde/

Blötner, C., Ziegler, M., Wehner, C., Back, M., \& Grosz, M. P. (2021). Open data, materials, and preregistration for "The nomological network of the Short Dark Tetrad Scale (SD4)”. https://osf.io/9ewjr/

Book, A., Visser, B. A., Blais, J., Hosker-Field, A., Methot-Jones, T., Gauthier, N. Y., Volk, A., Holden, R. R., \& D’Agata, M. T. (2016). Unpacking more "evil": What is at the core of the Dark Tetrad? Personality and Individual Differences, 90, 269-272. https://doi. org/10.1016/j.paid.2015.11.009

Brailovskaia, J., Bierhoff, H.-W., \& Margraf, J. (2019). How to identify narcissism with 13 items? Validation of the German Narcissistic Personality Inventory-13 (G-NPI-13). Assessment, 26(4), 630-644. https://doi.org/10.1177/1073191117740625
Buckels, E. E., Trapnell, P. D., Andjelovic, T., \& Paulhus, D. L. (2018). Internet trolling and everyday sadism: Parallel effects on pain perception and moral judgment. Journal of Personality, 87(2), 328-340. https://doi.org/10.1111/jopy.12393

Campbell, D. T., \& Fiske, D. W. (1959). Convergent and discriminant validation by the multitrait-multimethod matrix. Psychological Bulletin, 56(2), 81-105. https://doi.org/10.1037/ h0046016

Chabrol, H., van Leeuwen, N. V., Rodgers, R. F., \& Séjourné, N. (2009). Contributions of psychopathic, narcissistic, Machiavellian, and sadistic personality traits to juvenile delinquency. Personality and Individual Differences, 47(7), 734-739. https:// doi.org/10.1016/j.paid.2009.06.020

Champely, S., Ekstrom, C., Dalgaard, P., Gill, J., Weibelzahl, S. Anandkumar, A., Ford, C., Volcic, R., \& De Rosario, H. (2020). pwr: Basic functions for power analysis. Power analysis functions along the lines of Cohen (1988). https://cran.r-project.org/ web/packages/pwr/index.html

Christie, R., \& Geis, F. (1970). Studies in Machiavellianism. Academic Press.

Crowe, M. L., Lynam, D. R., Campbell, W. K., \& Miller, J. D. (2019). Exploring the structure of narcissism: Toward an integrated solution. Journal of Personality, 87(6), 1151-1169. https://doi. org/10.1111/jopy.12464

Cyders, M. A., Littlefield, A. K., Coffey, S., \& Karyadi, K. A. (2014). Examination of a short English version of the UPPS-P Impulsive Behavior Scale. Addictive Behaviors, 39(9), 1372-1376. https:// doi.org/10.1016/j.addbeh.2014.02.013

Cyders, M. A., Smith, G. T., Spillane, N. S., Fischer, S., Annus, A. M., \& Peterson, C. (2007). Integration of impulsivity and positive mood to predict risky behavior: Development and validation of a measure of positive urgency. Psychological Assessment, 19(1), 107-118. https://doi.org/10.1037/1040-3590.19.1.107

Dahling, J. J., Whitaker, B. G., \& Levy, P. E. (2009). The development and validation of a new Machiavellianism scale. Journal of Management, 35(2), 219-257. https://doi.org/10.1177/ 0149206308318618

Danner, D., Rammstedt, B., Bluemke, M., Treiber, L., Berres, S., Soto, C., \& John, O. (2016). Die deutsche Version des Big Five Inventory 2 (BFI-2) [The German version of the Big Five Inventory 2 (BFI-2)]. Zusammenstellung sozialwissenschaftlicher Items und Skalen. https://doi.org/10.6102/zis247

Dinić, B. M., Bulut Allred, T., Petrović, B., \& Wertag, A. (2020). A test of three sadism measures. Journal of Individual Differences, 41(4), 219-227. https://doi.org/10.1027/1614-0001/a000319

Enders, C. K. (2010). Applied missing data analysis. Guilford Press.

Funder, D. C., \& Ozer, D. J. (2019). Evaluating effect size in psychological research: Sense and nonsense. Advances in Methods and Practices in Psychological Science, 2(2), 156-168. https://doi.org/10.1177/2515245919847202

Furr, R. M., \& Heuckeroth, S. (2018). qcv: Quantifying construct validity. https://CRAN.R-project.org/package =qcv

Furr, R. M., \& Heuckeroth, S. (2019). The "quantifying construct validity" procedure: Its role, value, interpretations, and computation. Assessment, 26(4), 555-566. https://doi.org/10.1177/ 1073191118820638

GESIS. (2014). GESIS panel - Extended edition [Data set]. https:// doi.org/10.4232/1.12115

Gignac, G. E., \& Szodorai, E. T. (2016). Effect size guidelines for individual differences researchers. Personality and Individual Differences, 102, 74-78. https://doi.org/10.1016/j.paid.2016. 06.069

Gordts, S., Uzieblo, K., Neumann, C., Van den Bussche, E., \& Rossi, G. (2015). Validity of the Self-Report Psychopathy Scales (SRP-III full and short versions) in a community sample. Assessment, 24(3), 308-325. https://doi.org/10.1177/1073191115606205 
Grosz, M. P., Harms, P. D., Dufner, M., Kraft, L., \& Wetzel, E. (2020). Reducing the overlap between Machiavellianism and subclinical psychopathy: The M7 and P7 scales. Collabra: Psychology, 6(1), Article 17799. https://doi.org/10.1525/collabra.17799

Heene, M., Hilbert, S., Draxler, C., Ziegler, M., \& Bühner, M. (2011). Masking misfit in confirmatory factor analysis by increasing unique variances: A cautionary note on the usefulness of cutoff values of fit indices. Psychological Methods, 16(3), 319-336. https://doi.org/10.1037/a0024917

Henning, H. J., \& Six, B. (1977). Construction of a Machiavellianism scale [Konstruktion einer Machiavellismus-Skala]. Zeitschrift für Sozialpsychologie, 8, 185-198.

Hopwood, C. J., \& Donnellan, M. B. (2010). How should the internal structure of personality inventories be evaluated? Personality and Social Psychology Review, 14(3), 332-346. https://doi.org/10.1177/1088868310361240

Hu, L., \& Bentler, P. M. (1999). Cutoff criteria for fit indexes in covariance structure analysis: Conventional criteria versus new alternatives. Structural Equation Modeling, 6(1), 1-55. https:// doi.org/10.1080/10705519909540118

Jacobs, I., \& Scholl, W. (2016). IAL-K: Entwicklung einer Kurzform der Interpersonalen Adjektivliste [IAL-K: Development of a short-form of the Interpersonal Adjective List]. Diagnostica, 62(4), 227-241. https://doi.org/10.1026/0012-1924/a000156

Jones, D. N., \& Paulhus, D. L. (2011). Differentiating the Dark Triad within the interpersonal circumplex. In L. M. Horowitz \& S. Strack (Eds.), Handbook of interpersonal psychology: Theory, research, assessment, and therapeutic interventions (pp. 249-267). Wiley.

Keye, D., Wilhelm, O., \& Oberauer, K. (2009). Structure and correlates of the German version of the Brief UPPS Impulsive Behavior Scales. European Journal of Psychological Assessment, 25(3), 175-185. https://doi.org/10.1027/1015-5759.25.3.175

Lakens, D. (2017). Equivalence tests: A practical primer for t tests, correlations, and meta-analyses. Social Psychological and Personality Science, 8(4), 355-362. https://doi.org/10.1177/ 1948550617697177

Leckelt, M., Wetzel, E., Gerlach, T. M., Ackerman, R. A., Miller, J. D., Chopik, W. J., Penke, L., Geukes, K., Küfner, A. C. P., Hutteman, R., Richter, D., Renner, K.-H., Allroggen, M., Brecheen, C., Campbell, W. K., Grossmann, I., \& Back, M. D. (2018). Validation of the Narcissistic Admiration and Rivalry Questionnaire Short scale (NARQ-S) in convenience and representative samples. Psychological Assessment, 30(1), 86-96. https://doi.org/10.1037/pas0000433

Miller, J. D., Hyatt, C. S., Maples-Keller, J. L., Carter, N.T., \& Lynam, D. R. (2017). Psychopathy and Machiavellianism: A distinction without a difference? Journal of Personality, 85(4), 439-453. https://doi.org/10.1111/jopy.12251

Morf, C. C., \& Rhodewalt, F. (2001). Unraveling the paradoxes of narcissism: A dynamic self-regulatory processing model. Psychological Inquiry, 12(4), 177-196.

Moshagen, M., Hilbig, B. E., \& Zettler, I. (2014). Faktorenstruktur, psychometrische Eigenschaften und Messinvarianz der deutschsprachigen Version des 60-Item HEXACO Persönlichkeitsinventars [Factor structure, psychometric properties and measurement invariance of the German version of the 60item HEXACO Personality Inventory]. Diagnostica, 60(2), 86-97. https://doi.org/10.1026/0012-1924/a000112

Muris, P., Merckelbach, H., Otgaar, H., \& Meijer, E. (2017). The malevolent side of human nature: A meta-analysis and critical review of the literature on the Dark Triad (narcissism, Machiavellianism, and psychopathy). Perspectives on Psychological Science, 12(2), 183-204. https://doi.org/10.1177/1745691616666070
Paulhus, D. L., Buckels, E. E., Trapnell, P. D., \& Jones, D. N. (2020). Screening for dark personalities: The Short Dark Tetrad (SD4). European Journal of Psychological Assessment,. Advance Online Publication. https://doi.org/10.1027/10155759/a000602

Paulhus, D. L., Curtis, S., \& Jones, D. N. (2018). Aggression as a trait: The Dark Tetrad alternative. Current Opinion in Psychology, 19, 88-92. https://doi.org/10.1016/j.copsyc.2017.04.007

Paulhus, D. L., \& Jones, D. N. (2015). Measures of dark personalities. In G. J. Boyle, D. H. Saklofske, \& G. Matthews (Eds.), Measures of personality and social psychological constructs (pp. 562-594). Elsevier Academic Press. https://doi.org/10.1016/ B978-0-12-386915-9.00020-6

Paulhus, D. L., \& Williams, K. M. (2002). The Dark Triad of personality: Narcissism, Machiavellianism, and psychopathy. Journal of Research in Personality, 36(6), 556-563. https://doi. org/10.1016/S0092-6566(02)00505-6

Penke, L. (2011). Revised Sociosexual Orientation Inventory. In T. D. Fisher, C. M. Davis, W. L. Yarber, \& S. L. Davis (Eds.), Handbook of sexuality-related measures (3rd ed., pp. 622-625). Routledge.

Rosseel, Y. (2012). lavaan: An R Package for Structural Equation Modeling. Journal of Statistical Software, 48(2), 1-36. https:// doi.org/10.18637/jss.v048.i02

Schönbrodt, F. D., \& Gerstenberg, F. X. R. (2012). An IRT analysis of motive questionnaires: The Unified Motive Scales. Journal of Research in Personality, 46(6), 725-742. https://doi.org/ 10.1016/j.jrp.2012.08.010

Schönbrodt, F. D., \& Perugini, M. (2013). At what sample size do correlations stabilize? Journal of Research in Personality, 47(5), 609-612. https://doi.org/10.1016/j.jrp.2013.05.009

Skeem, J. L., Polaschek, D. L. L., Patrick, C. J., \& Lilienfeld, S. O. (2011). Psychopathic personality. Psychological Science in the Public Interest, 12(3), 95-162. https://doi.org/10.1177/1529100611426706

Southard, A. C., Noser, A. E., Pollock, N. C., Mercer, S. H., \& Zeigler-Hill, V. (2015). The interpersonal nature of dark personality features. Journal of Social and Clinical Psychology, 34(7), 555-586. https://doi.org/10.1521/jscp.2015.34.7.555

Suessenbach, F., Loughnan, S., Schönbrodt, F. D., \& Moore, A. B. (2019). The dominance, prestige, and leadership account of social power motives. European Journal of Personality, 33(1), 7-33. https://doi.org/10.1002/per.2184

van Buuren, S. (2020). mice: Multivariate imputation by chained equations (version 3.11.0). https://cran.r-project.org/web/ packages/mice/index.html

Vize, C. E., Lynam, D. R., Collison, K. L., \& Miller, J. D. (2018). Differences among Dark Triad components: A meta-analytic investigation. Personality Disorders: Theory, Research, and Treatment, 9(2), 101-111. https://doi.org/10.1037/per0000222

von Collani, G., \& Herzberg, P. Y. (2003). Eine revidierte Fassung der deutschsprachigen Skala zum Selbstwertgefühl von Rosenberg [A revised version of the German adaptation of Rosenberg's self-esteem scale]. Zeitschrift für Differentielle und Diagnostische Psychologie, 24(1), 3-7. https://doi.org/10.1024/ 0170-1789.24.1.3

Wehner, C., Maaß, U., Leckelt, M., Back, M. D., \& Ziegler, M. (2020). Validation of the Short Dark Triad in a German sample: Structure, nomological network, and an ultrashort version. European Journal of Psychological Assessment. Advance online publication. https://doi.org/10.1027/1015-5759/a000617

Werner, R., \& von Collani, G. (2014). Deutscher Aggressionsfragebogen [German Aggression Scale]. Zusammenstellung sozialwissenschaftlicher Items und Skalen. https://doi.org/10.6102/ zis52 
Whiteside, S. P., \& Lynam, D. R. (2001). The Five-Factor Model and impulsivity: Using a structural model of personality to understand impulsivity. Personality and Individual Differences, 30(4), 669-689. https://doi.org/10.1016/S0191-8869(00)00064-7

Zimmermann, J., Altenstein, D., Krieger, T., Grosse Holtforth, M., Pretsch, J., Alexopoulos, J., Spitzer, C., Benecke, C., Krueger, R. F., Markon, K., \& Leising, D. (2014). The structure and correlates of self-reported DSM-5 maladaptive personality traits: Findings from two German-speaking samples. Journal of Personality Disorders, 28(4), 518-540. https://doi.org/ 10.1521/pedi_2014_28_130

\section{History}

Received September 29, 2020

Revision received February 15, 2021

Accepted March 4, 2021

Published online June 16, 2021

EJPA Section / Category Personality

\section{Publication Ethics}

This study received approval from the institutional review board of the University of Münster.

\section{Open Science}

We report how we determined our sample size, all data exclusions (if any), all data inclusion/exclusion criteria, whether inclusion/ exclusion criteria were established prior to data analysis, all measures in the study, and all analyses including all tested models. If we use inferential tests, we report exact $p$-values, effect sizes, and 95\% confidence or credible intervals.

Open Data: We confirm that there is sufficient information for an independent researcher to reproduce all of the reported results, including the codebook if relevant (Blötner et al., 2021).

Open Materials: We confirm that there is sufficient information for an independent researcher to reproduce all of the reported methodology (Blötner et al., 2021).

Preregistration of Studies and Analysis Plans: This study was preregistered with an analysis plan. All data, materials, and preregistration can be retrieved from https://osf.io/9ewjr/ (Blötner et al., 2021).

\section{Funding}

Open Access publication enabled by TU Dortmund University.

\section{ORCID}

Christian Blötner

(iD https://orcid.org/0000-0001-7415-4756

\section{Christian Blötner}

Faculty for Educational Sciences and Psychology

Department of Psychology

TU Dortmund University

Emil-Figge-Str. 50

44227 Dortmund

Germany

christian.bloetner@tu-dortmund.de 


\section{Appendix}

\section{German SD4}

Table A1. German translations of the SD4

\begin{tabular}{|c|c|}
\hline Item labels & German item content \\
\hline Mach_1 & Es ist nicht ratsam, seine Geheimnisse preiszugeben. \\
\hline Mach_2 & Man muss die wichtigen Personen auf seine Seite ziehen, koste es, was es wolle. \\
\hline Mach_3 & Vermeide direkte Konflikte mit Anderen, denn sie könnten in der Zukunft von Nutzen sein. \\
\hline Mach_4 & Verhalte dich unauffällig, wenn du deinen Willen durchsetzen willst. \\
\hline Mach_5 & Die Situation zu manipulieren, erfordert Planung. \\
\hline Mach_6 & Schmeicheln ist ein gutes Mittel, um Leute auf deine Seite zu ziehen. \\
\hline Mach_7 & Ich liebe es, wenn ein kniffliger Plan gelingt. \\
\hline Narc_1 & Andere sehen mich als geborene Führungsperson. \\
\hline Narc_2 & Ich habe eine einzigartige Begabung, andere zu überzeugen. \\
\hline Narc_3 & Gruppenaktivitäten sind ohne mich eher langweilig. \\
\hline Narc_4 & Ich weiß, dass ich etwas Besonderes bin, da mir andere das immer wieder sagen. \\
\hline Narc_5 & Ich habe einige außergewöhnliche Qualitäten. \\
\hline Narc_6 & Ich werde in der Zukunft wahrscheinlich ein Star in einem bestimmten Bereich sein. \\
\hline Narc_7 & Ich mag es, hin und wieder anzugeben. \\
\hline Psyc_1 & Menschen sagen oft, dass ich außer Kontrolle bin. \\
\hline Psyc_2 & Ich neige dazu, gegen Autoritäten und deren Regeln zu kämpfen. \\
\hline Psyc_3 & Ich war in mehr Auseinandersetzungen verwickelt als die meisten Menschen meines Alters und Geschlechts. \\
\hline Psyc_4 & Ich neige dazu, mich kopfüber in etwas zu stürzen ohne Fragen zu stellen. \\
\hline Psyc_5 & Ich hatte schon Schwierigkeiten mit dem Gesetz. \\
\hline Psyc_6 & Ich gerate manchmal in gefährliche Situationen. \\
\hline Psyc_7 & Leute, die sich mit mir anlegen, bereuen es immer \\
\hline Sad_1 & Bei einem Faustkampf zuzuschauen begeistert mich. \\
\hline Sad_2 & Ich genieße gewalttätige Filme und Computerspiele. \\
\hline Sad_3 & Es ist witzig, wenn Idioten auf die Nase fallen. \\
\hline Sad_4 & Ich genieße es, bei gewalttätigem Sport zuzuschauen. \\
\hline Sad_5 & Manche Menschen verdienen es zu leiden. \\
\hline Sad_6 & Rein zum Vergnügen habe ich schonmal gemeine Dinge in sozialen Medien gesagt. \\
\hline Sad_7 & Ich weiß, wie ich jemanden allein mit Worten verletzen kann. \\
\hline
\end{tabular}

Note. Mach = Machiavellianism; Narc = Narcissism; Psyc = Psychopathy; Sad = Sadism. 